\title{
Экономизация политики как следствие политического кризиса модерна
}

Одной из обращающих на себя внимание характеристик современного общества как общества постмодерна является скептическое отношение к метанарративам. Напомним, что концепция метанарратива была предложена французским философом Ж.-Ф. Лиотаром в работе "Состояние постмодерна: доклад о знании" в 1979 г.; метанарратив у Лиотара - характерный для общества модерна способ дискурсивной легитимации социальных структур, одновременный ответ на вопрос "что верно" и "что справедливо" [5, с. 27-33]. К числу метанарративов Лиотар относил христианство, социализм, рационализм Просвещения, сциентизм, идеи исторического прогресса, эмансипации, т.д. [3]. В XX в. метанарратив как способ легитимации привёл к появлению тоталитарных идеологий, следствием чего, в свою очередь, стал всплеск скептического отношения к любым универсалистским повествованиям, частичное крушение "проекта модерна" и переход к постмодерну.

Основываясь на характеристике общества постмодерна как общества отказа от метанарративов мы можем пойти дальше и сказать, что для постмодерна характерна замена целеполагания стремлением к развитию. Под целеполаганием здесь понимается деятельность, направленная на достижение заранее определённого состояния общества (зачастую идеального, а следовательно, полностью недостижимого, что не отменяет возможности стремиться максимально приблизиться к определённому идеалу); таким образом, целеполагание носит этический характер. Стремление к развитию - деятельность, направленная на достижения состояния общества, в котором происходит постоянный рост объективных (обычно экономических, в силу простоты их подсчёта) показателей, и эта деятельность носит экономический (ориентированный на максимизацию выгоды) характер.

Нам представляется, что такой отказ от целеполагания связан с изменением представлений о сущности политики, который мы назовём переходом от концепции "политики-этики" к концепции "политики-экономики".

Классическим для западной традиции является представление о государстве как структуре, воплотившей некоторое идеальное представление о благе, а мерилом проекта мыслилось соответствие государства заранее сфрормулированному идеальному образцу. Родоначальником подобного взгляда на государство является Платон: "Когда властителями в государстве станут подлинные философы... нынешними почестями они пренебрегут, считая их низменными и ничего не стоящими, и будут высоко ценить порядочность и ту честь, что с нею связана, но самым великим и необходимым будут считать справедливость; служа ей и умножая её, устроят они своё государство" [6, c. 326]. С некоторыми модификациями такое понимание политики получилось развитие у Аристотеля: "Понятие справедливости связано с представлением о государстве, так как право, служащее мерилом справедливости, является регулирующей нормой политического общения" [1, с. 379]. Примеры такого отношения можно найти в политических редормах, последовавших за Великой Французской революцией (которые можно рассматривать как реализацию всей политической программы Просвещения). Как высшее воплощение объективного духа трактовал государство Гегель. Наконец, это же представление господствовало в самодетерминации социалистических и националистических режимов $\mathrm{XX}$ в.

СМИРНОВ Илья Олегович, магистрант Дальневосточного федерального университета (2. Владивосток). E-mail: SmirnovIlya1998@gmail.com 
Причиной подобного представления стал ещё более глубокий философрский паттерн - представление о политике как о продолжении этики. Ещё в XVII в. в Европе считалось, что правитель должен руководствоваться не интересами государства (reasons of state, считавшиеся слишком макиавеллистским концептом), а христианскими представлениями о нравственности [13, с. 367368]. Такой подход к управлению также соответствует и более современному восприятию политических отношений. Немецкий политолог Бернхард Сутор указывает на то, что во властных отношениях всегда есть коммуникативный элемент, не сводимый к праву силы - даже тоталитарные режимы, де-фракто правящие принуждением, всё равно стараются создать видимость собственной легитимности [8, с. 100-103].

Такой подход удобен для государства во многих отношениях, но он обнаруживает и ряд побочных проблем, одна из которых заключается в том, что в рамках концепции "политика-этика" противостояние господствующей политической программе является также противостоянием стремлению к благу, что приводит к дегуманизации несогласных с господствующей политикой. Отсюда вытекали репрессии против инакомыслящих, которые автоматически мыслились как аморалы. Таких людей ради общего (и их собственного) блага можно лишить большинства политических прав, собственности, свободы и даже жизни. В наиболее показательной форме это было выражено в определениях "врага народа" в социалистической системе и "национал-предателя" в нацистской Германии.

В тоталитарных режимах XX в. трансформация образа политической оппозиции из "другого" в "чужого" достигла своего апогея, за которым последовало диалектически неумолимое отрицание. А именно: всеобщее подчинение человеческой жизни стремлению к благу в реальности вырождается в диктатуру партийной элиты, узурпировавшей право определять суть понятия "благо", что вызывает кризис всей концепции политики как продолжения этики. Доведённое до полной теоретической непротиворечивости, государство, построенное вокруг концепции "политики-этики", оказалось ужасающим для рядового гражданина, за чем последовал призыв отказаться от теоретических схем, т.е. от идеологии, а соответственно и от власти идеологов. Маятник качнулся в обратную сторону: любая попытка ввести этическое в сферу политики вызывает подозрения в злом умысле в виде стоящего за идеологическими конструкциями частного интереса [9, с. 238-239].

На смену концепции "политика-этика" приходит понимание политики как взаимодействия преследующих личный интерес субъектов, обладающих ресурсами для достижения этого интереса. Такое определение политики схоже с господствующими определениями экономики [12], отсюда предложенный нами термин "политика-экономика". Концепции технократического государства как построения государства на основе научно-технического знания появляется задолго до второй половины XX в.; к наиболее известным можно отнести утопический социализм А. Сен-Симона (XIX в.), технократическое государство Т. Веблена (начало XX в.) [2]. Отличительная черта нового этапа - обоснование легитимности концепции технократического государства не столько через максимизацию общественной выгоды, сколько через стремление к построению, пользуясь термином Фуко, "места справедливости" - социальной системы, свободной от произвола и регулируемой нормами, основанными на объективных фрактах [10, с. 48]. Постмодерн не просто восстановил концепцию технократического государства - он восстановил её в виде превращённой формы. За исчерпанием кредита доверия идеологам последовал призыв передать власть технократам.

Подобный призыв подразумевает распространение на политику экономического принципа невмешательства в детерминированные объективными законами экономического развития системные процессы, основанные на некоторых "очевидностях" (наподобие повышения благосостояния), следование этим объективным законам и в сфере политики, что приводит к стиранию границ между политикой и экономикой и к переходу политики на твёрдую почву экономической объективности. Яркий пример такого перехода - неолиберальный поворот в политике, произошедший в 70-ых в ряде западных государств. Теоретиком неолиберального поворота стал Ф.А. фрон Хайек. С точки зрения неолиберализма наличие цели на уровне государства создаёт необходимость 
коррекции, если в результате ошибок планирование не позволяет достигнуть этой цели. Но так как государство постоянно совершает ошибки в планировании, потребуется постоянная коррекция, чего можно достигнуть только ценой отказа от свободы общества, его подчинения всесильному государству. Единственный способ сохранить свободу - отказаться от постановки цели как таковой [11, с. 104-112].

Однако модель "политика-экономика" также быстро обнаружила ряд проблем. Несмотря на стирание границы между экономикой и политикой в современном мире, эти две сферы общественной жизни имеют различный характер. Со времён античности экономика носит инструментальный характер - само слово с древнегреческого переводится как "заведование домашним хозяйством", набор навыков, необходимый для управления земельным наделом. B XVI-XVII вв. резкое ускорение накопления капитала приводит к появлению экономики как науки, изучающей правила торговли и производства $[4$, c. 30 31]. Таким образом, экономика всегда отвечает на вопрос "как достигнуть цели?", но не на вопрос о том "как поставить цель?", а следовательно, конечное обоснование экономической деятельности всегда будет возможно только вне экономики, в сфере политического, этического, религиозного, эстетического, т.д. Экономика всегда может существовать только как подсистема в рамках другой социальной системы. Даже сформулированная в терминах "воспроизводства общества", "устойчивого развития", "продолжения существования системы" цель является не экономической, а этической - так как базируется на установке о том, что воспроизводство системы (этноса, нации, общества) является благом. Угроза растворения этики в экономической технике и теории достаточно хорошо проиллюстрирована у уже упомянутого Б. Сутора - приводя пример принятия политического решения, развития системы медицинского страхования, он чётко разделяет техническую составляющую этого решения ("какими методами может быть улучшена такая система?") и этическую ("нужна ли такая система, кто имеет право претендовать на медицинскую страховку и в какой мере?") [8, с. 19-20]. Политика, в отличие от экономики, носит автономный (самостоятельный) характер, так как способна ставить конечные цели (а не только промежуточные), не выходя за свои же пределы.

Иными словами, в связи с инструментальным характером экономики, общество, отказавшееся от целеполагания, правильнее было бы назвать обществом скрытого целеполагания. Стремление к благу, политическое по своей природе, прежде существовавшее в таких классических формах, как следование идее блага, божественному завету или самопознанию абсолютного духа, обернулось превращённой формой "объективных и очевидных истин" наподобие стремления человека к повышению своего благосостояния, росту экономических возможностей и потребления.

Ирония превращённой формы привела к тому, что к обществу "политики-экономики" оказались применимы всё те же принципы, что и к обществу "политики-этики" с заменой "действующих лиц": диктат идеологии заменяется диктатом "объективных и очевидных истин". Соответственно, восстающий против господствующих представлений - уже не враг народа, но глупец или идеалист (в негативном значении этого слова), не понимающий объективных законов функционирования экономики, политики, общества. Его уже нельзя просто так лишить жизни, свободы и собственности. Но он, в духе Фуко, всё ещё подобен ребёнку или душевнобольному - в том смысле, что непонимание им очевидных истин представляет угрозу для окружающих: из этого, например, следует возможность ограничить его доступ к политической власти.

Отсюда же вытекает ещё одна характеристика общества "политики-экономики". Для такого общества всегда характерен империалистический характер любой проводимой им политики. Под империализмом нами понимается техника политического управления, постулирующая необходимость постоянного расширения за счёт постановки своих интересов перед интересами других субъектов.

Наша логика следующая. Основа общества "политики-экономики" "объективные и очевидные истины", с одной стороны, де-факто является этической конструкцией, с другой - поскольку одной из причин перехода к "политике-экономике" стало разочарование в этике, она не должна казаться таковой. "Объективные и очевидные истины" одновременно удовлетворяют 
нескольким критериям "объективности и очевидности": а) избегать фрормулировки в этических терминах (наподобие "благосостояние есть благо"), иначе они получат клеймо идеологемы или мифологемы; б) быть основанными на объективных фрактах, иначе они опять же будут названы идеологическим построением; в) быть интуитивно понятными и принимаемыми большинством людей без необходимости приведения дополнительных доказательств, иначе их этический в действительности характер будет вскрыт в ходе пристального рассмотрения.

Таким критериям соответствует индивидуальный экономический интерес. Для всех живых существ характерно стремление к самосохранению, а также получению как можно большего ресурса с как можно меньшей затратой энергии - за счёт этого стремление удовлетворить личный экономический интерес интуитивно понятно и близко индивиду; само наличие такого интереса обусловлено природными (стремление к сохранению ресурса, биология) и социальными (наличие интереса как условие хозяйственной деятельности, экономика) фракторами; наконец, такая обусловленность естественными фракторами позволяет сформулировать очевидную истину экономического интереса в неэтических терминах - не "следование личному экономическому интересу это благо", а "следование личному экономическому интересу это естественно для человека и эфффективно для экономики", где "естественно" и "эфрфективно" всё ещё понимается как синоним блага, но в явном виде таковым не называется. Экономический интерес - это то самое благо, скрытая, неназываемая цель, к которой должна стремиться "политика-экономика", и, также как для "политики-этики" мерилом эффрективности является соответствие Истине; в новом обществе таким мерилом является экономическая эфорективность, что было нехарактерно для концепций технократического государства эпохи модерна. Веблен проводил легитимацию своего социального проекта путём указания на то, что рост производственных сил в обществе ведёт к трансформации социальной структуры, снижению "хищнических наклонностей" в поведении (термин Веблена, близкий к используемому нами термину "империализм" - постулирование необходимости максимизации прибыли вместе с игнорированием интересов окружающих), к росту солидаризации социума в целях решения общих проблем, даже если подобная солидаризация не несёт прямой выгоды для индивида [14].

Любая этическая система может быть представлена как цепочка логических утверждений, следующих друг из другом, в основе же такой цепочки и лежит благо, первичное утверждение, рационально не выводимое ни из чего другого. Первичное утверждение является предпосылкой к определённым действиям, ответом на вопрос "как поставить цель?", но не на вопрос "как достигнуть поставленной цели?"; таким образом, производные утверждения должны соотноситься с эмпирическими фактами, и должны изменяться вместе с изменяющимися условиями жизни, в отличие от первичного утверждения о том, что есть благо: данное утверждение является вневременным, а взятое в объективно-идеалистическом смысле, ещё и независимым от эмпирии.

В качестве примера такой системы можно привести построение, основанное на гуманистической установке о сакральности человеческой жизни. Тезис о сакральности жизни человека в такой этической системе будет первичным утверждением, из которого последует необходимость построения правового и социального государства (как системы институтов, защищающих неприкосновенность жизни), следующее звено - необходимость создания юридической и пенсионной систем как элементов правового и социального государства, и т.д. С другой стороны, в XIX в. социальное государство в современном понимании было бы невозможно из-за более низкого уровня технического и экономического развития, следовательно, производные из тезиса о сакральности человеческой жизни были бы другими - например, необходимость создания системы социальных лифтов. В христианском обществе, где человек есть Божье творение, следствия также отличались бы. Этот список можно продолжать ещё долго, но общее правило - первичное утверждение всегда будет оставаться одним и тем же, а вот производные меняются, так как они зависят от условий среды - уже продемонстрировано.

"Политика-экономика", являясь, как было выяснено, этической системой, подчиняется этому правилу, но с одной важной модификацией. Так как 
первичная установка носит в ней скрытый характер, она может сливаться в восприятии с одной из производных. Иными словами, над тезисом "следование личному экономическому интересу это естественно для человека и эфрективно для экономики" встанет ещё более приоритетный тезис "естественность и эфрфективность - это благо". Иными словами, благо всегда окажется содержанием первичной установки, в т.ч. в системе "политика-экономика".

Кажущаяся слабость "политики-этики" - отсутствие обоснования первичной установки, из чего следует невозможность объективного, рационального спора с ней - на самом деле является её сильной стороной, так как позволяет подвергнуть такую систему сомнению, при этом сомнению изнутри. Равенство первичных установок этических систем приводит к тому, что при столкновении различных этосов любое действие - сохранение приверженности той этике, к которой индивид принадлежал ранее, или же смена этической установки - переживается как выбор. Выбор - понятие, всегда связываемое с ответственностью, следовательно, всё, что связано с этическим в человеческой жизни, является формой ответственности индивида. Экономизм, заменяющий этику на экономику и создающий видимость обоснования первичной установки, таким образом, одновременно постулирует (пусть и в неявной форме), что следование личному интересу, воплощённое в империализме как специфической технике управления есть благо, но при этом снимает с человека какую-либо ответственность за последствия следования этой ценности - в силу её якобы объективности. Попытка уйти от идеологии путём отказа от субъективности в этике, таким образом, превращается в свою антитезу - ещё больший субъективизм, теперь прикрытый налётом объективности. То, что теперь стало невозможным требование ответственности за принятие первичной установки, в свою очередь, стало угрозой для предполагаемой теоретиками постмодерна солидаризацией на основе общих ценностей в противовес абсолютной истине идеологии [7], солидаризацией, которая в действительности принимает форму корпоративизации, разделения людей на группы на основе общих экономических интересов.

Кризис политического проекта модерна во второй половине XX в. выступил в качестве цивилизационного вызова, ответом на который стал переход к концепции "политики-экономики". Подобная трансформация восприятия политики позволила преодолеть некоторые слабости классической концепции "политики-этики", однако основная проблема - наличие фундаменталистских тенденций в современной политической мысли - так и осталась нерешённой; критика "политики-этики" как со стороны мыслителей неолиберального направления, так и со стороны теоретиков постмодерна, утверждающих необходимость множественности дискурсов, в полной мере может быть обращена в сторону "политики-экономики". Следует признать, что концепция "политики-экономики" не является полноценным, завершённым решением политического кризиса модерна.

В завершение кратко упомянем возможные варианты разрешения данного кризиса. Этот вопрос в целом выходит за рамки настоящей статьи и заслуживает полноценного рассмотрения в отдельных работах, поэтому видится разумным наиболее обще определить перспективные направления развития. Таковых можно выделить два.

Во-первых, это возвращение к концепции "политики-этики" с её последующей модификащией. Основной проблемой политического проекта модерна было не столько влияние этики на принятие решения (оно присутствует и в "политике-экономике"), сколько склонность такой системы к идеализации доминирующей в обществе этической концепции и подавлению любого несогласия с ней. Этический плюрализм, понимание принципиального равенства различных этических концепций вкупе с механизмами организации политического диалога внутри общества может выступить инструментом предотвращения радикализации политического проекта модерна. Набирающие популярность концепции "новой этики" и "новой искренности" можно отнести как раз к попытке возвращения этики в процесс принятия политических решений.

Во-вторых, это дальнейшее развитие концепции "политики-экономики", переводящее этику из сферы общественных отношений в сферу личной жизни, контролирующей связи с непосредственным кругом общения человека: друзьями, коллегами, единоверцами. Этический компонент в принятии поли- 
тических решений не будет полностью устранён, но может быть минимизирован, оставляя пространство для свободы совести в личной жизни. Современная концепция "культурного разнообразия", предполагающая существование множества религиозных, этнических, идеологических и иных групп, находящихся в частично изолированном друг от друга состоянии, но при этом проживающих в одном обществе выступает примером такого подхода к принятию политических решений.

\section{Литература}

1. Аристотель. Соч.: в 4 т. Т. 4. М.: Мысль, 1983. 830 с.

2. Бычков, С.Ю. Представление об элите в технократических концепциях XX века / С.Ю. Бычков // Вестник Нижегородского университета им. Н.И. Лобачевского. Серия Социальные науки, 2011. № 2 (22). С. 25-30.

3. Волков, В.Н. Постмодерн: недоверие к метанарративам /В.Н. Волков // Культурное наследие России, 2015. № 2. С. 3-11.

4. Кузнецова, М.В. История экономических учений как отражение эволюции общества / М.В. Кузнецова // Вестник ОГУ, 2007. № 4. С. 28-35.

5. Лиотар, Ж.-Ф. Состояние постмодерна. С.-П.: Алетейя, 1998. 160 с.

6. Платон. Государство. Соч.: в 4 т. Т. 3. М.: Мысль, 1994. 654 с.

7. Рорти, Р. Случайность, ирония и солидарность. М.: Русское феноменологическое общество, 1996. $282 \mathrm{c.}$

8. Сутор, Б. Малая политическая этика / Б. Сутор; пер. С.М. Курбатова, К. Н. Костюк. М.: Директ-Медиа, 2013. 138 с.

9. Трунов А.А. Идеология в обществах модерна и постмодерна: сравнительный анализ / А.А. Трунов // Научные ведомости БелгГУ. Сер. Философия. Социология. Право, 2019. Т. 44. № 2. С. 234-243.

10. Фуко, М. Рождение биополитики. Курс лекций, прочитанных в Коллеж де Франс в 1978-1979 учебном году / М. Фуко; пер. с фр. А. В. Дьяков. СПб.: Наука, 2010. $448 \mathrm{c.}$ $264 \mathrm{c}$.

11. Хайек, Фридрих Август фон. Дорога к рабству. М.: Новое издательство, 2005.

12. Backhouse R., Medema S. Retrospectives: on the definition of economics. Journal of economic perspectives, 2009. Vol 23. № 1. P. 221-233.

13. Croxton, Derek. Westphalia, the Last Cristian peace. New York: Palgrave Macmillan, 2013. $452 \mathrm{p}$.

14. Nesterov A., Azimli A. Technocratic ideology in the Dessauer's philosophy of technology. / SHS Web of Conferences, 2019. Vol 72. URL: https://www.shs-conferences. org/articles/shsconf/pdf/2019/13/shsconf_appsconf2019_01007.pdf.

\section{Транслитерация по ГОСТ 7.79-2000 система Б}

1. Aristotel'. Soch.: v 4 t. T. 4. M.: Mysl', 1983. 830 s.

2. Bychkov, S.YU. Predstavlenie ob ehlite v tekhnokraticheskikh kontseptsiyakh XX veka / S.YU. Bychkov // Vestnik Nizhegorodskogo universiteta im. N.I. Lobachevskogo. Seriya Sotsial'nye nauki, 2011. № 2 (22). S. 25-30.

3. Volkov, V.N. Postmodern: nedoverie k metanarrativam /V.N. Volkov // Kul'turnoe nasledie Rossii, 2015. № 2. S. 3-11.

4. Kuznetsova, M.V. Istoriya ehkonomicheskikh uchenij kak otrazhenie ehvolyutsii obshhestva / M.V. Kuznetsova // Vestnik OGU, 2007. № 4. S. 28-35.

5. Liotar, ZH.-F. Sostoyanie postmoderna. S.-P.: Aletejya, 1998. $160 \mathrm{~s}$.

6. Platon. Gosudarstvo. Soch.: v 4 t. T. 3. M.: Mysl', 1994. $654 \mathrm{~s}$.

7. Rorti, R. Sluchajnost', ironiya i solidarnost'. M.: Russkoe fenomenologicheskoe obshestvo, 1996. $282 \mathrm{~s}$.

8. Sutor, B. Malaya politicheskaya ehtika / B. Sutor; per. S.M. Kurbatova, K. N. Kostyuk. M.: Direkt-Media, 2013. 138 s.

9. Trunov A.A. Ideologiya $\mathrm{v}$ obshhestvakh moderna i postmoderna: sravnitel'nyj analiz / A.A. Trunov // Nauchnye vedomosti BelgGU. Ser. Filosofiya. Sotsiologiya. Pravo, 2019. T. 44. № 2. S. 234-243.

10. Fuko, M. Rozhdenie biopolitiki. Kurs lektsij, prochitannykh v Kollezh de Frans v 1978-1979 uchebnom godu / M. Fuko; per. s fr. A. V. D'yakov. SPb.: Nauka, 2010. 448 s.

11. KHajek, Fridrikh Avgust fon. Doroga k rabstvu. M.: Novoe izdatel'stvo, 2005. $264 \mathrm{~s}$.

12. Backhouse R., Medema S. Retrospectives: on the definition of economics. Journal of economic perspectives, 2009. Vol 23. № 1. P. 221-233. 
13. Croxton, Derek. Westphalia, the Last Cristian peace. New York: Palgrave Macmillan, 2013. $452 \mathrm{p}$.

14. Nesterov A., Azimli A. Technocratic ideology in the Dessauer's philosophy of technology. / SHS Web of Conferences, 2019. Vol 72. URL: https://www.shs-conferences.org/ articles/shsconf/pdf/2019/13/shsconf_appsconf2019_01007.pdff.

\section{кризиса модерна. \\ Смирнов И. О. Экономизация политики как следствие политического}

Процесс перехода от концепции политики как продолжения этики к концепции политики как продолжения экономики явился результатом кризиса политического проекта модерна второй половины XX века. Экономизация политики возникла как способ устранения этического начала из сферы политического, что было связано с восприятием этического начала как источника субъективности в политике и основной причины появления тоталитарных режимов в XX веке. При этом прикладной, инструментальный характер экономики не оставляют возможности избежать обращения к определённому этическому идеалу как основе организации политики. Процесс экономизации политики, таким образом, не устраняет этическое начало из политики, а лишь переводит его в скрытое состояние.

Ключевые слова: политическая фбилософбия, этизация политики, эконолизация политики, политический кризис модерна, постмодерн

Smirnov I. O. Economization of politics as a result of the political crisis of modernity.

The transition from the concept of politics as a continuation of ethics to the concept of politics as a continuation of economics was a result of a political crisis of modernity in the second half of the XXth century. Economization of politics stated as a way of eliminating ethical principles from political sphere, that in turn were seen as a source of a subjectivity in politics, and the main reason of a resurgence of totalitarian states in the XXth century. But the practical, instrumental nature of economics doesn't give other options but to use certain ethical ideal as a basis for organizing political sphere. Thus, the process of economization of a political sphere doesn't actually eliminate ethical principles, but only hide it from sight.

Key words: political philosophy, ethization of politics, economization of politics, political crisis of modernity, postmodernity

Для цитирования: Смирнов И. О. Экономизация политики как следствие политического кризиса модерна // Ойкумена. Регионоведческие исследования. 2021. № 4. С. 130-136. DOI: $10.24866 / 1998-6785 / 2021-4 / 130-136$

For citation: Smirnov I. O. Economization of politics as a result of the political crisis of modernity // Ojkumena. Regional researches. 2020. № 1. P. 130-136. DOI: 10.24866/19986785/2021-4/130-136 